\title{
Effect of bilirubin on cytochrome c oxidase activity of mitochondria from mouse brain and liver
}

\author{
Safarina G Malik*1, K Astrid Irwanto1, J Donald Ostrow² and Claudio Tiribelli ${ }^{3}$
}

\begin{abstract}
Background: The unbound, free concentration $\left(B_{f}\right)$ of unconjugated bilirubin (UCB), and not the total UCB level, has been shown to correlate with bilirubin cytotoxicity, but the key molecular mechanisms accounting for the toxic effects of UCB are largely unknown.

Findings: Mouse liver mitochondria increase unbound UCB oxidation, consequently increasing the apparent rate constant for unbound UCB oxidation by HRP (Kp), higher than in control and mouse brain mitochondria, emphasizing the importance of determining $\mathrm{Kp}$ in complete systems containing the organelles being studied. The in vitro effects of UCB on cytochrome coxidase activity in mitochondria isolated from mouse brain and liver were studied at $B_{f}$ ranging from 22 to $150 \mathrm{nM}$. The results show that UCB at $B_{f}$ up to $60 \mathrm{nM}$ did not alter mitochondrial cytochrome coxidase activity, while the higher concentrations significantly inhibited the enzyme activity by $20 \%$ in both liver and brain mitochondria.

Conclusions: We conclude that it is essential to include the organelles being studied in the medium used in measuring both $\mathrm{Kp}$ and $\mathrm{B}_{\mathrm{f}}$. A moderately elevated, pathophysiologically-relevant $\mathrm{B}_{\mathrm{f}}$ impaired the cytochrome c oxidase activity modestly in mitochondria from mouse brain and liver.
\end{abstract}

\section{Backgrounds}

Unconjugated bilirubin (UCB) at low concentrations is a potent antioxidant [1,2] that is neuroprotective [3], while higher levels of UCB may damage neurons and astrocytes [3-6], resulting in bilirubin-induced neurological dysfunction (BIND) in some neonates with severe unconjugated hyperbilirubinemia. It has been shown that the unbound, free concentration $\left(\mathrm{B}_{\mathrm{f}}\right)$ of unconjugated bilirubin (UCB), and not the total UCB level, correlates with bilirubin cytotoxicity [7], but the key molecular mechanisms accounting for the toxic effects of UCB are largely unknown. Although the primary subcellular targets for the toxic effects of UCB are not fully identified, mitochondria are believed to be particularly vulnerable $[4,8$ 12]. However, with few exceptions $[10,13]$, most prior research was performed at unbound UCB concentrations $\left(\mathrm{B}_{\mathrm{f}}\right)$ orders of magnitude higher than its hypothesized upper normal limit of $20 \mathrm{nM}(1.2 \mu \mathrm{g} / \mathrm{dL})$ in plasma of

* Correspondence: ina@eijkman.go.id

1 Eijkman Institute for Molecular Biology, Jl. Diponegoro 69, Jakarta 10430, Indonesia

Full list of author information is available at the end of the article term infants [14]. In addition, most studies used unpurified commercial bilirubin, rendering uncertain whether the observed toxic effects were due to UCB itself, or to contaminants (especially lipids).

Here we demonstrate the need to include the organelles being studied in the medium used in measuring both $\mathrm{Kp}$ and $\mathrm{B}_{\mathrm{f}}$. This study further describe the in vitro effect of $\mathrm{UCB}$, at $\mathrm{B}_{\mathrm{f}}$ ranging from 22 to $150 \mathrm{nM}$, on cytochrome $c$ oxidase (E.C. 1.9.3.1) activity in mitochondria isolated from mouse liver and brain. Cytochrome $c$ oxidase is a crucial enzyme in aerobic energy metabolism, serving as the final electron acceptor complex in the mitochondrial electron transport. It catalyzes electron transfer from cytochrome $c$ to molecular oxygen, reducing the latter to water, and yields substantial energy that drives the formation of a proton gradient that is then employed to synthesize cellular ATP [15]. The absence, deficiency or malfunction of this enzyme in human leads to a number of serious disease states [16]. The results obtained in this study are relevant to the in vivo impairment of mitochondrial function by elevated plasma levels of UCB. 


\section{Materials and methods Materials}

Bilirubin (Sigma Chemical Co.-Aldrich, Milan, Italy) was purified using the method of McDonagh and Assisi [17]. Phenylmethanesulfonyl Fluoride (PMSF), p-Aminobenzamidine dihydrochloride (PAB $\mathrm{HCl}$ ), $\varepsilon$-Amino-n-Caproic Acid ( $\varepsilon$-ACA), n-dodecyl $\beta$-D-maltoside, L-ascorbic acid, horseradish peroxidase (Type 1 HRP, EC.1.11.1.7), cytochrome $c$ from horse heart, and Bovine Serum Albumin (BSA) fraction V (Fatty-acid free) were purchased from Sigma Aldrich (St. Louis, MO, USA). Reagent grade hydrogen peroxide $\left(\mathrm{H}_{2} \mathrm{O}_{2}, 30 \% \mathrm{wt} / \mathrm{vol}\right)$, hydrochloric acid $(\mathrm{HCl}, 37 \%)$, chloroform, sodium hydroxide and sucrose were purchased from Merck (Darmstadt, Germany). EDTA (disodium salt, dehydrate, crystal) was purchased from BDH (Dorset, England). Tris was purchased from Invitrogen (Carlsbad, CA, USA). HEPES was purchased from Gibco BRL (Grand Island, NY, USA).

\section{Reagents}

Purified UCB was dissolved in chloroform $(0.5 \mathrm{mg} / \mathrm{mL})$ and the concentrations $(\mu \mathrm{g} / \mathrm{mL})$ determined spectrophotometrically as $\mathrm{A}_{453 \mathrm{~nm}} \times 0.974 \times$ dilution factor [17]. UCB was divided into $50 \mu \mathrm{g}$ and $300 \mu \mathrm{g}$ aliquots, and the chloroform evaporated under nitrogen at $<65^{\circ} \mathrm{C}$, and stored at $-20^{\circ} \mathrm{C}$ until used. UCB was dissolved either in $0.01 \mathrm{~N}$ $\mathrm{NaOH}$ for Kp measurement or $0.5 \%$ vol/vol DMSO for $\mathrm{B}_{\mathrm{f}}$ measurement and Complex IV Assay. $\mathrm{H}_{2} \mathrm{O}_{2}(1 \%)$ was prepared freshly each day by diluting $33.3 \mu \mathrm{L}$ of $30 \% \mathrm{H}_{2} \mathrm{O}_{2}$ with $967 \mu \mathrm{L}$ of potassium phosphate buffer, $\mathrm{pH}$ 7.4. HRP stock solution $(1 \mathrm{mg} / \mathrm{mL})$ was prepared by dissolving 1 mg HRP in $1 \mathrm{~mL}$ potassium phosphate buffer, $\mathrm{pH} 7.4$, and stored at $-20^{\circ} \mathrm{C}$. Mitochondria isolation buffers are as described in [18] for liver mitochondria and in [19] for brain mitochondria. Cytochrome $c$ was reduced by Lascorbate according to the method of [20]. Full reduction of cytochrome $c$ was confirmed by measuring the absorbance at 550 and $560 \mathrm{~nm}$.

\section{Methods}

Isolation of mitochondria from mouse liver (LM) and brain (BM) were obtained by sacrificing six BALB/c mice (8-10 weeks) by decapitation (approved by the Eijkman Institute Research Ethics Commission). LM isolation was as in [18], and brain mitochondria (BM) isolation was as in [19]. Mitochondrial protein concentration was determined by the modified Lowry Protein Assay [21]. Determination of unbound bilirubin $\left(\mathrm{B}_{\mathrm{f}}\right)$ was performed using the minimally-diluted peroxidase method [22] with modification [23]. Unbound bilirubin was oxidized by peroxide $\left(\mathrm{H}_{2} \mathrm{O}_{2}\right)$ in the presence of horseradish peroxidase (HRP) with first-order kinetics, while albumin-bound bilirubin was not [24]. The preliminary standardization of the rate constant $(\mathrm{Kp})$ for oxidation of unbound UCB was done by measuring the decrease in $\mathrm{A}_{440}$ following addition of $\mathrm{HRP}$ and $\mathrm{H}_{2} \mathrm{O}_{2}$ in a system containing buffer, UCB, and $100 \mu \mathrm{g}$ of brain or liver mitochondria in the absence of albumin [22-24]. Unbound bilirubin $\left(\mathrm{B}_{\mathrm{f}}\right)$ was determined in a complete system containing buffer, BSA, UCB, and $100 \mu \mathrm{g}$ of brain or liver mitochondria, by measuring the decrease in $\mathrm{A}_{468}$ in the presence of HRP and $\mathrm{H}_{2} \mathrm{O}_{2} . \mathrm{B}_{\mathrm{f}}$ was calculated from $\mathrm{Kp}$, the HRP concentration, and the initial change of light absorbance peak at $468 \mathrm{~nm}$ over time [23,24]. Triplicate determinations were performed for each measurement, and $\mathrm{Kp}$ or $\mathrm{Bf}$ was determined from the average of at least three mitochondrial preparations.

Cytochrome $c$ oxidase activity was measured at $37^{\circ} \mathrm{C}$ as described previously, using $100 \mu \mathrm{g}$ of brain or liver mitochondria [20,25], and expressed as percent activity normalized to control incubations at the same BSA concentration but without UCB. The oxidation of cytochrome $c$ by cytochrome $c$ oxidase was followed spectrophotometrically at $550 \mathrm{~nm}$ for $30 \mathrm{~s}$, assuming $\varepsilon^{1 \mathrm{~cm}}=$ 19,600 per mol for horse heart cytochrome $c$ [26]. The effect of purified UCB on the activity of cytochrome $c$ oxidase was studied at low (22-31 nM and 60-61 nM) and high (92-107 $\mathrm{nM}$ and 142-150 nM) $\mathrm{B}_{\mathrm{f}}$ concentrations.

Results for LM and BM were the average of triplicate determinations performed at each $\mathrm{B}_{\mathrm{f}}$ level. All data are expressed as mean \pm SD of at least 3 experiments obtained in 3 different preparations of mitochondria. Statistical differences were calculated according to the twotailed Student's t-test, performed on the basis of equal or unequal variance as appropriate. $p$ values lower than 0.05 were considered statistically significant.

\section{Results and Discussion}

Liver mitochondria increase the oxidation of unbound UCB Measurement of the rate constant for oxidation of unbound UCB by HRP (Kp, 15-20 repeats) was performed both in the absence and presence of BM or LM; controls were the assay mixture without mitochondria. Kp determination was needed to calculate unbound bilirubin concentration $[23,24]$. The mean control $\mathrm{Kp}$ values were unaffected by addition of BM, but were 1.7 times higher in the presence of LM (Table 1). The $\mathrm{B}_{\mathrm{f}}$ calculation was, therefore, based on the Kp value obtained with each experimental condition (control, with LM, and with BM).

As reported in Table 2, addition of $0.5 \mathrm{mM}$ potassium cyanide $(\mathrm{KCN})$, a cytochrome $c$ oxidase inhibitor, decreased $\mathrm{Kp}$ to control values $(\mathrm{p}<0.01)$ in the presence of LM; the decrease was even greater when the KCN concentration was increased to $1.0 \mathrm{mM}$. The dose-dependent $\mathrm{Kp}$ inhibition induced by $\mathrm{KCN}$ was much less prominent in assay mixtures containing BM. 
Table 1: Effect of brain mitochondria (BM) and liver mitochondria (LM) on rate of peroxidation of unbound UCB by HRP (Kp)

\begin{tabular}{lcc}
\hline & $\begin{array}{c}\text { Kp } \\
(\mathbf{m L} \cdot \boldsymbol{\mu g}-\mathbf{1} \cdot \mathbf{m i n}-\mathbf{1})\end{array}$ & vs control (p) \\
\hline $\operatorname{Control}^{a}(\mathrm{n}=22)$ & $0.406 \pm 0.01$ & 0.183 \\
$\mathbf{B M} b(\mathrm{n}=15)$ & $0.399 \pm 0.02$ & $<0.001$ \\
$\mathbf{L M} c(\mathrm{n}=16)$ & $\mathbf{0 . 6 9 9} \pm \mathbf{0 . 0 3}$ & \\
\hline
\end{tabular}

Kp was determined by method described in [23], to measure the coupled constant rate of bilirubin oxidation by HRP. ${ }^{a}$ Control, no mitochondria; ${ }^{b} \mathbf{B M}$, mouse brain mitochondria; $c \mathbf{L M}$, mouse liver mitochondria.

The higher $\mathrm{Kp}$ values and the decrease of $\mathrm{Kp}$ due to $\mathrm{KCN}$ addition in the presence of LM indicate that LM contain higher levels of intrinsic peroxidases than BM, confirming previous studies [27]. It has been reported that BM contains bilirubin oxidase, which also has been detected in other organs including liver $[28,29]$. Other peroxidases known to be present in mitochondria include phospholipid hydroperoxide glutathione peroxidase (PHGPx) [30], glutathione peroxidase (GPx), catalase (CAT) [30,31], and peroxiredoxin (Prx) III [32], which like other hemoproteins, are inhibitable by $\mathrm{KCN}[29,31]$. In LM, these intrinsic mitochondrial peroxidases contribute to the UCB oxidation measured in the presence of the added HRP, accounting for the almost $2 \times$ higher apparent $\mathrm{Kp}$ in the presence of LM compared to BM. These findings emphasize the importance of determining $\mathrm{Kp}$ in complete systems containing the organelles being studied.
Effects of $B_{f}$ on mitochondrial cytochrome c oxidase activity $\mathrm{B}_{\mathrm{f}}$ was varied by using various $\mathrm{B} / \mathrm{A}$ molar ratios $(\mathrm{r})$ and two different BSA concentrations (Table 3). As expected, the $B_{f}$ increased with $r$, with a tendency to slightly higher measured $\mathrm{B}_{\mathrm{f}}$ in systems containing $\mathrm{LM}$ compared to BM. Except for $\mathrm{r}=0.35(p=0.215)$, these differences were significant $(p<0.005$ for $\mathrm{r}=0.2 ; p=<0.005$ for $\mathrm{r}=0.5$; $p<$ 0.005 for $\mathrm{r}=0.75$ ).

The mean value of $B_{f}$ from 4-5 replicate tubes was utilized in assessing the effects of increasing $\mathrm{B}_{\mathrm{f}}$ on cytochrome $c$ oxidase activity. As shown in Table 4, the exposure of mitochondria to $\mathrm{B}_{\mathrm{f}}$ of 22-31 nM and 60-61 $\mathrm{nM}$ was not associated with any significant effect on cytochrome $c$ oxidase activity of either BM or LM as compared to control. In contrast, $\mathrm{B}_{\mathrm{f}}$ of $92-107 \mathrm{nM}$ and 142-150 nM caused significant, comparable reductions (18-20\%) of cytochrome $c$ oxidase activity in both BM and LM; no significant difference was found between the inhibition observed at mean $\mathrm{B}_{\mathrm{f}}$ values of 100 and $146 \mathrm{nM}$. In vivo the brain and liver mitochondria are exposed to

Table 2: KCN inhibition of rate of peroxidation of unbound UCB by HRP (Kp)

\begin{tabular}{|c|c|c|}
\hline \multicolumn{3}{|c|}{ Relative Kpa } \\
\hline & vs control & vs LMb or BMc \\
\hline Control $(n=18)$ & $100 \pm 3.1$ & \\
\hline $0.5 \mathrm{mM} \mathrm{KCN}(\mathrm{n}=12)$ & $84.7 \pm 5.8(p<0.001)$ & \\
\hline $1.0 \mathrm{mM} \mathrm{KCN}(\mathrm{n}=11)$ & $73.4 \pm 5.8(p<0.001)$ & \\
\hline $\mathbf{B M}^{b}(n=11)$ & $99.2 \pm 4.4(p=0.618)$ & \\
\hline $0.5 \mathrm{mM} \mathrm{KCN}(\mathrm{n}=6)$ & $88.7 \pm 3.3(p<0.001)$ & $89.4 \pm 3.4(p<0.001)$ \\
\hline $1.0 \mathrm{mM} \mathrm{KCN}(\mathrm{n}=6)$ & $72.1 \pm 6.8(p<0.001)$ & $72.1 \pm 6.9(p<0.001)$ \\
\hline $\operatorname{LM}^{c}(\mathbf{n}=12)$ & $172 \pm 6.2(p<0.001)$ & \\
\hline $0.5 \mathrm{mM} \mathrm{KCN}(\mathrm{n}=6)$ & $102 \pm 8.1(p=0.580)$ & $59.4 \pm 4.7(p<0.001)$ \\
\hline $1.0 \mathrm{mM} \mathrm{KCN}(\mathrm{n}=6)$ & $83.8 \pm 9.3(p<0.001)$ & $48.8 \pm 5.4(p<0.001)$ \\
\hline
\end{tabular}

a Percent of Kp values normalized to control (no mitochondria); ${ }^{b} \mathbf{B M}$, mouse brain mitochondria; $\mathbf{C} \mathbf{L M}$, mouse liver mitochondria. 
Table 3: Measured unbound bilirubin $\left(B_{f}\right)$ concentrations at various ratios of $[U C B] /[B S A]$

\begin{tabular}{|c|c|c|c|c|c|}
\hline \multirow[b]{2}{*}{$\begin{array}{l}\text { UCB/BSA Ratio, } \\
\text { [BSA] } \mu \mathrm{M}\end{array}$} & \multicolumn{3}{|l|}{$B f(n M)$} & \multirow[b]{2}{*}{$\begin{array}{c}p \text {-value } \\
\text { (BM vs LM) }\end{array}$} & \multirow[b]{2}{*}{$\begin{array}{c}p \text {-value } \\
\text { (control vs LM) }\end{array}$} \\
\hline & Control $^{a}$ & $\mathrm{BM}^{b}$ & LMc & & \\
\hline $0.20,60$ & $22.3 \pm 3.4$ & $22.6 \pm 2.2$ & $30.8 \pm 2.2$ & $p<0.005$ & $p<0.005$ \\
\hline $0.35,60$ & $61.4 \pm 2.3$ & $59.6 \pm 2.0$ & $61.5 \pm 4.3$ & $p=0.215, \mathrm{NS}$ & $p=0.788, \mathrm{NS}$ \\
\hline $0.50,60$ & $90.2 \pm 2.6$ & $93.4 \pm 5.6$ & $104 \pm 4.6$ & $p<0.005$ & $p<0.005$ \\
\hline $0.75,30$ & $141 \pm 3.9$ & $142 \pm 3.4$ & $150 \pm 6.3$ & $p<0.005$ & $p<0.005$ \\
\hline
\end{tabular}

cytosolic fluid in which $B_{\mathrm{f}}$ is much lower than in plasma [33]. These results suggest that cytochrome $c$ oxidase activity is probably only minimally impaired at plasma unbound bilirubin concentrations found during neonatal jaundice. Given that cytochrome $c$ oxidase is a crucial enzyme in aerobic energy metabolism, and deficiency or malfunction of this enzyme in human leads to a number of serious disease states, changes caused by high $\mathrm{B}_{\mathrm{f}}$ concentration may cause noticeable damage and alter the whole mitochondrial function. Others have reported recently that the cytochrome $c$ oxidase activity in rat cortical neurons was decreased by approximately $50 \%$ due to exposure to $50 \mu \mathrm{M}$ UCB in the presence of $100 \mu \mathrm{M}$ HSA [34]. This gives an estimated $B_{f}$ of $119 \mathrm{nM}$ [35], midway between the two highest $B_{f}$ values we studied. The difference in the degree of inhibition they observed might be due to the differences between rat and mouse mitochondria, as well as the differences of the systems used. Vaz et al [34] exposed cultured neuronal cells to UCB, then iso- late the mitochondria afterwards, while this study directly exposed isolated mitochondria from whole brain consisiting of a mixture of cells, including neurons and glial cells. It has been reported that neurons respond differently from glial cells to bilirubin induced toxicity $[29,36,37]$. In particular, the rate of bilirubin oxidation was reported to be significantly lower in mitochondrial membranes from a pure neuronal source than membranes from either a glial source or a mixed neuronal/ glial source [29], hence the higher sensitivity of neurons to UCB induced toxicity as compared to glial cells.

\section{Conclusions}

We showed that, in the application of the peroxidase method, it is important to determine $\mathrm{Kp}$, the first order rate constant for HRP-catalyzed UCB oxidation by peroxide in the absence of albumin; Kp is then used to calculate $\mathrm{B}_{\mathrm{f}}$, in a complete system containing the organelles being studied. As demonstrated in this study, liver mitochondria increase the oxidation of unbound UCB, thus

Table 4: Cytochrome c oxidase activity of mouse liver and brain mitochondria exposed to different free bilirubin ( $\left.B_{f}\right)$ concentrations

Percent Activity (\%) vs controla

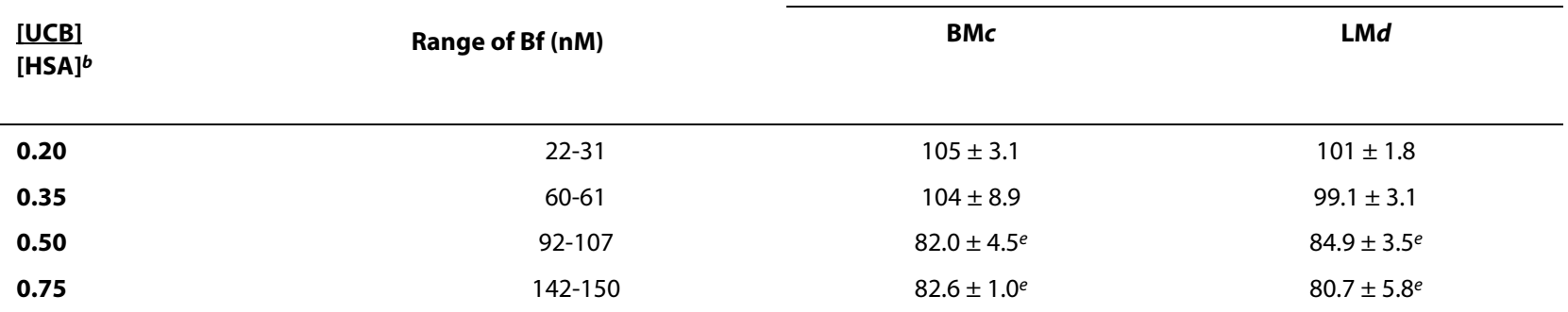

a Results are means of three repeats of at least three separate measurements of the activity of cytochrome coxidase activity as percent of control (no UCB). ${ }^{b}$ Molar ratios of bilirubin to albumin (r). ${ }^{c}$ Mouse liver mitochondria. ${ }^{d}$ Mouse brain mitochondria. ${ }^{e}$ All $p<0.001$ vs. $B_{\mathrm{f}}=22-$ $31 \mathrm{nM}$, and $p<0.05$ vs $\mathrm{B}_{\mathrm{f}}=60-61 \mathrm{nM}$, respectively. No significant differences between: $\mathrm{B}_{\mathrm{f}}=22-31 \mathrm{nM}$ vs. $\mathrm{B}_{\mathrm{f}}=60-61 \mathrm{nM}(p=0.936$ for $\mathrm{BM}$ and $p=0.302$ for $\mathrm{LM}$ ); $\mathrm{B}_{\mathrm{f}}=92-107 \mathrm{nM}$ vs. $\mathrm{B}_{\mathrm{f}}=142-150 \mathrm{nM}(p=0.791$ for $\mathrm{BM}$ and $p=0.342$ for $\mathrm{LM})$; or BM vs. $\mathrm{LM}$ at any range of $\mathrm{B}_{\mathrm{f}}(p=0.086, p=$ $0.372, p=0.298, p=0.605$, respectively). 
increasing the apparent $\mathrm{Kp}$. As stated at the beginning of this paper, $B_{f}$ has been shown to correlate with bilirubin cytotoxicity. $B_{f}$ measurement using the peroxidase method could improve the clinical management of neonatal jaundice by better recognizing babies that need treatment and minimizing unnecessary intervention [38].

The present study, using purified UCB at pathophysiologically relevant $\mathrm{B}_{\mathrm{f}}$ concentrations, demonstrated that at modestly elevated $B_{f}$ concentrations (about 90 and 150 $\mathrm{nM}$ ), UCB inhibits cytochrome $c$ oxidase activity by about $20 \%$ in both brain and liver mitochondria from mice. Exposure to lower, but still elevated $B_{f}$ up to about approx. $60 \mathrm{nM}$ did not significantly affect mitochondrial cytochrome $c$ oxidase activity in either BM or LM. The lack of a progressive dose-response effect as $B_{f}$ increased from approx. 100 to $150 \mathrm{nM}$, as well as the modest $20 \%$ impairment in cytochrome $c$ oxidase activity, suggests that impairment of mitochondrial oxidative activity might not be a major factor in the toxic effects of UCB on these organelles. The results do not negate the reports by others that UCB alters mitochondrial function in other ways $[9,11]$, for example by altering mitochondrial membrane potential and triggering apoptosis by release of cytochrome $c$ into the cytosol.

Our studies, done at $\mathrm{B}_{\mathrm{f}}$ levels compatible with those in the plasma of jaundiced neonates, did not confirm the suggested greater sensitivity of BM than LM to toxic effects of $\mathrm{UCB}$, derived from studies at vastly higher UCB concentrations [7], although it is important to bear in mind that the source of the brain mitochondria used in this study are a mixture of various type of cells, not only the ones that are sensitive to bilirubin toxicity, such as neuronal cells, but also the less sensitive ones, such as glial cells [29]. These less sensitive cells might be masking the effect of bilirubin toxicity to the level similar to that of liver mitochondria.

The present work thus demonstrates the importance of comparing effects of UCB at comparable $\mathrm{B}_{\mathrm{f}}$ levels, measured using the peroxidase method. It also demonstrates the need to include the organelles in the medium used in measuring both $\mathrm{Kp}$ and $\mathrm{B}_{\mathrm{f}}$.

\section{Competing interests}

The authors declare that they have no competing interests.

\section{Authors' contributions}

SGM designed the study, established and performed Bf determinations and cytochrome c oxidase assay, performed data analysis, wrote and revised the final manuscript. KAl performed Bf determinations, cytochrome $c$ oxidase assay, data analysis, and wrote the manuscript. JDO and CT provided direction and oversight of the experiments, and helped revise the final manuscript. All authors read and approved the final manuscript.

\section{Acknowledgements}

We thank Drs. Sebastián D. Calligaris, Pablo Giraudi and Leslye Roca for bilirubin purification. This work was supported by TWAS Research Grants program in Basic Sciences (Research Grant Agreement (RGA) No. 05-064 RG/BIO/AS).

\section{Author Details}

${ }^{1}$ Eijkman Institute for Molecular Biology, Jl. Diponegoro 69, Jakarta 10430, Indonesia, ${ }^{2} \mathrm{Gl} /$ Hepatology Division, Dept. Medicine, University of Washington, Seattle, WA, 98195, USA and ${ }^{3}$ CSF AREA Science Park and Dept. ACADEM, University of Trieste, 34012, Trieste, Italy

Received: 13 April 2010 Accepted: 9 June 2010

Published: 9 June 2010

\section{References}

1. Stocker R, Yamamoto Y, McDonagh AF, Glazer AN, Ames BN: Bilirubin is an antioxidant of possible physiological importance. Science 1987, 235:1043-1046.

2. Sedlak TW, Snyder SH: Bilirubin benefits: cellular protection by a biliverdin reductase antioxidant cycle. Pediatrics 2004, 113:1776-1782.

3. Dore S, Snyder SH: Neuroprotective action of bilirubin against oxidative stress in primary hippocampal cultures. Ann NY Acad Sci 1999, 890:167-172.

4. Cowger ML, Igo RP, Labbe RF: The mechanism of bilirubin toxicity studied with purified respiratory enzyme and tissue culture systems. Biochem 1965, 4:2763-2770.

5. Ahlfors CE: Bilirubin-albumin binding and free bilirubin. J Perinatol Supl 2001, 21:40-42.

6. Ostrow JD, Pascolo L, Brites D, Tiribelli C: Molecular basis of bilirubininduced neurotoxicity. Trends Mol Med 2004, 10:65-70.

7. Calligaris S, Bellarosa C, Giraudi P, Wennberg RP, Ostrow JD, Tiribelli C: Cytotoxicity is predicted by unbound and not total bilirubin concentration. Pediatr Res 2007, 62:576-580.

8. Mustafa MG, Cowger ML, King TE: Effects of bilirubin on mitochondrial reactions. J Biol Chem 1969, 244:6403-6414.

9. Noir BA, Boveris A, Garaza AM Pereira, Stoppani AO: Bilirubin: a multi-site inhibitor of mitochondrial respiration. FEBS Lett 1972, 27:270-274.

10. Rodrigues CMP, Solá S, Silva R, Brites D: Bilirubin and amlyloid- $\beta$ peptide induce cytochrome $c$ release through mitochondrial membrane permeabilization. Mol Med 2000, 6:936-946.

11. Rodrigues CMP, Solá S, Brites D: Bilirubin induces apoptosis via the mitochondrial pathway in developing rat brain neurons. Hepatol 2002, 35:1186-1195

12. Rodrigues CMP, Solá S, Brito MA, Brites D, Moura JJG: Bilirubin directly disrupts membrane lipid polarity and fluidity, protein order, and redox status in rat mitochondria. J Hepatol 2002, 36:335-341.

13. Silva RFM, Mata LR, Gulbenkian S, Brito A, Tiribelli C, Brites D: Inhibition of glutamate uptake by unconjugated bilirubin in cultured rat astrocytes: role of concentration and pH. Biochem Biophys Res Commun 1999, 265:67-72.

14. Wennberg RP, Ahlfors CE, Bhutani VK, Johnson LH, Shapiro SM: Toward understanding kernicterus: a challenge to improve management of jaundiced newborns. Pediatrics 2006, 117:474-485.

15. Capaldi RA: Structure and assembly of cytochrome $c$ oxidase. Arch Biochem Biophys 1990, 280:252-262.

16. Sarnat HB, Marín-García J: Pathology of mitochondrial encephalomyopathies. Can J Neurol Sci 2005, 32:152-166.

17. McDonagh AF, Assisi F: The ready isomerization of bilirubin-IXa in aqueous solution. Biochem J 1972, 129:797-800.

18. Towers NR, Dixon H, Kellerman GM, Linnane AW: Biogenesis of mitochondria. 22. The sensitivity of rat liver mitochondria to antibiotics; a phylogenetic difference between a mammalian system and yeast. Arch Biochem Biophys 1972, 151:361-369.

19. Sims NR: Mitochondrial isolation from brain: strategy, techniques, and criteria for purity. Method Toxicol 1993, 2:29-40.

20. Trounce IA, Kim YL, Jun AS, Wallace DC: Assessment of mitochondrial oxidative phosphorylation in patient muscle biopsies, lymphoblasts and transmitochondrial cell lines. Method Enzymol 1996, 264:484-509.

21. Lowry OH, Rosebrough NJ, Farr AL, Randall RJ: Protein measurement with the Folin phenol reagent. J Biol Chem 1951, 193:265-275.

22. Ahlfors CE: Measurement of Plasma Unbound Unconjugated Bilirubin. Anal Biochem 2000, 279:130-135.

23. Roca L, Calligaris S, Wennberg RP, Ahlfors CE, Malik SG, Ostrow JD, Tiribelli C: Factors affecting the binding of bilirubin to serum albumins: validation and application of the peroxidase method. Pediatr Res 2006, 60:724-728 
24. Jacobsen J, Wennberg RP: Determination of unbound bilirubin in the serum of newborns. Clin Chem 1974, 20:783-789.

25. Yonetani T: Studies on cytochrome $c$ peroxidase. II.Stoichiometry between enzyme, $\mathrm{H}_{2} \mathrm{O}_{2}$, and ferrocytochrome $c$ and enzymic determination of extinction coefficients of cytochrome $c$. J Biol Chem 1965, 240:4509-4514.

26. Capaldi RA, Marusich MF, Taanman JW: Mammalian cytochrome-c oxidase: characterization of enzyme and immunological detection of subunits in tissue extracts and whole cells. Method Enzymol 1995, 260:117-132.

27. Patel SP, Katyare SS: A comparative study of reactive oxygen species (ROS) related parameters in rat tissues. Ind J Clin Biochem 2006, 21:48-53.

28. Brodersen R, Bartels P: Enzymatic oxidation of bilirubin. Eur J Biochem $1969,10: 468-473$

29. Hansen TW, Allen JW: Oxidation of bilirubin by brain mitochondrial membranes--dependence on cell type and postnatal age. Biochem Mol Med 1997, 60:155-160.

30. Panfili E, Sandri G, Ernster L: Distribution of glutathione peroxidases and glutathione reductase in rat brain mitochondria. FEBS Lett 1991, 290:35-37.

31. Salvi M, Battaglia V, Brunati AM, La Rocca N, Tibaldi E, Pietrangeli P, Marcocci L, Mondovi B, Rossi AC, Toninello A: Catalase takes part in rat liver mitochondria oxidative stress defense. J Biol Chem 2007. 282:24407-24415.

32. Chang TS, Cho CS, Park S, Yu S, Kang SW, Rhee SG: Peroxiredoxin III, a mitochondrion-specific peroxidase, regulates apoptotic signaling by mitochondria. J Biol Chem 2004, 279:41975-41984.

33. Zelenka J, Lenícek M, Muchová L, Jirsa M, Kudla M, Balaz P, Zadinová M, Ostrow JD, Wong RJ, Vítek L: Highly sensitive method for quantitative determination of bilirubin in biological fluids and tissues. $J$ Chromatogr B Analyt Technol Biomed Life Sci 2008, 867:37-42.

34. Vaz AR, Delgado-Esteban M, Brito MA, Bolaños JP, Brites D, Almeida A: Bilirubin selectively inhibits cytochrome $c$ oxidase activity and induces apoptosis in immature cortical neurons: assessment of the protective effects of glycoursodeoxycholic acid. J Neurochem 2010, 112:56-65.

35. Weisiger RA, Ostrow JD, Koehler RK, Webster CC, Mukerjee P, Pascolo L, Tiribelli C: Affinity of human serum albumin for bilirubin varies with albumin concentration and buffer composition: results of a novel ultrafiltration method. J Biol Chem 2001, 276:29953-29960.

36. Notter MF, Kendig JW: Differential sensitivity of neural cells to bilirubin toxicity. Exp Neurol 1986, 92:670-682.

37. Silva RF, Rodrigues CM, Brites D: Rat cultured neuronal and glial cells respond differently to toxicity of unconjugated bilirubin. Pediatr Res 2002, 51:535-541.

38. Ahlfors CE, Wennberg RP, Ostrow JD, Tiribelli C: Unbound (free) bilirubin (Bf): Improving the paradigm for evaluating neonatal jaundice. Clin Chem 2009, 55:1288-1299.

doi: 10.1186/1756-0500-3-162

Cite this article as: Malik et al., Effect of bilirubin on cytochrome c oxidase activity of mitochondria from mouse brain and liver BMC Research Notes 2010, 3:162

\section{Submit your next manuscript to BioMed Central} and take full advantage of:

- Convenient online submission

- Thorough peer review

- No space constraints or color figure charges

- Immediate publication on acceptance

- Inclusion in PubMed, CAS, Scopus and Google Scholar

- Research which is freely available for redistribution

Submit your manuscript at www.biomedcentral.com/submit
C Biomed Central 